\title{
Anacronismo, stásis y el olvido de la democracia: las Erinias al pie del Areópago
}

\author{
Luis Armando Hernández Cuevas
}

\section{Anacronismo histórico}

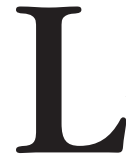

as líneas a continuación tienen la intención de zanjar una de las tantas problemáticas exploradas en los escritos de Nicole Loraux. La vehemencia de la problemática a tratar es tal, que sus vientos siguen acechando, y a veces parecieran arrancar de raíz instancias que se mostraban inamovibles. Así pues, los vientos a los cuales nos referimos son las corrientes formadas por un olvido generalizado por la democracia: la

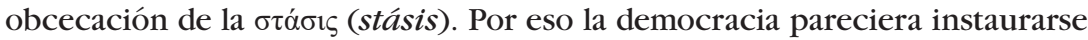
como el centro; como el ojo de un huracán que ante su pasividad, olvida que su espacialidad sosegada no es más que el epifenómeno de agitaciones intempestivas. Es de nuestro parecer que en ello reside la gran intuición de Loraux. La helenista francesa logró establecer, gracias a su combate permanente con la bestia negra del historiador, es decir, con el anacronismo, un diálogo entre el tiempo presente y la Antigüedad. Un diálogo que obliga a poner en entredicho

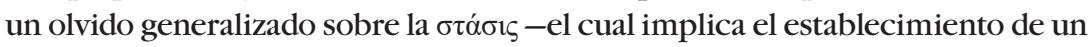
espacio-tiempo político que negando sus características emergentes, de cariz agónico, instaura un pasaje calmo como principio original y fundamento de todo su devenir-que permea y se repite diferencialmente en múltiples épocas.

Junto a Loraux, nos encontramos en una instancia en la que tenemos que perder el miedo al anacronismo. Más allá de la imprudencia bajo la que se podría caracterizar este método, la helenista asevera que "para un historiador de la Antigüedad, el presente es el motor más eficaz de la pulsión de entender". ${ }^{1}$ La audacia del historiador reside en asumir el riesgo del anacronismo. La pregunta entonces es: ¿cómo asumir el riesgo sin abolir la rigurosidad? Para

${ }^{1}$ Nicole Loraux, La guerra civil en Atenas. La política entre la sombra y la utopía. Trad. de Ana Iriarte. Madrid, Akal, p. 203. 
Loraux, afirmar un determinado modo del anacronismo implica cuestionarse desde dónde es que habla el historiador: ¿cuál es su campo epistemológico?, ¿cuál es la atmósfera?, ¿cuáles son los sentimientos; las afecciones que interpela?, del mismo modo que resulta imperante preguntarse por los campos epistemológicos, por la atmósfera, por las afecciones de lo otro en tanto que campo de experimentación. Así, de lo que se trata es del intento por desplegar una práctica controlada del anacronismo. Producir prácticas disyuntivas que posibiliten intuir las afecciones dispuestas en las cartografias históricas. Loraux afirma:

Para acercarse a la antigua Grecia, hay que hacer uso del anacronismo, a condición de que el historiador asuma el riesgo de plantearle a su objeto griego precisamente cuestiones que ya no sean griegas. A condición de que acepte someter su "material" antiguo a preguntas que los antiguos no se plantearon o, al menos, no formularon o, mejor todavía, no llegaron a desmenuzar como tales. ${ }^{2}$

La incursión intempestiva del historiador en el juego del anacronismo requiere de la mayor prudencia, así como de una gran capacidad de movilidad. Capacidad de desplazamiento espacio-temporal. El problema no es resolver, ni esbozar causalmente el plano antiguo estudiado. El problema es experimentar el campo asumido, es volver al presente con problemas antiguos. De ahí que la apuesta de Loraux - la cual acompañaremos- sea reflexionar sobre "los 'problemas griegos de la democracia moderna'".3

A todo esto: ¿cuál es el problema central que acecha a la democracia moderna? El problema que acecha a la democracia moderna desde los problemas griegos tiene una fecha marcada: el 403 a. C. En este año, bajo agitaciones propias del devenir intensivo y contingente de esa época, se propició un juramento, tras la victoria de los demócratas contra la sangrienta dictadura oligárquica de los Treinta, que hace eco en muchos y heterogéneos movimientos diferenciales en aquello que, bajo una lógica generalizadora, se denomina como democracia. El juramento es simple, no obstante, su acepción es integral: "hay que olvidar las desgracias del pasado”. La cuestión anacrónica reside entonces en discutir cómo es que este eco retumba diferencialmente en movimientos contingentes y azarosos en la cartografía intensiva que compone la historia de la democracia. ¿A qué se apela con este olvido? Olvidar los asesinados, las proscripciones, los estados de excepción, todo por mor de un espacio-tiempo sereno, de una legitimidad simulada y de una paz asentada en un principio

\footnotetext{
${ }^{2}$ Ibid., p. 207.
}

${ }^{3}$ Ibid., p. 203. 
ficcional. El olvido diferencial y anacrónico de la democracia pareciera ser la apuesta por una amnistía que, haciendo tabula rasa, permite que una determinada población, que un territorio explícito, olvide incluso lo inolvidable. La resonancia diferencial del olvido del 403 a. C. es la autoprohibición significante de una sociedad que pretende desasirse de los males; de los espectros; de la huellas. Loraux señala que una particular forma de anacronismo es "la atención a lo repetitivo". ${ }^{4}$ Bajo esta premisa, ¿acaso lo repetitivo no puede ser, en sus múltiples expresiones, una repetición diferencial del espectro; del simulacro; de aquello que es velado en el discurso significante? Una voz que se suma y que con mayor peso apunta hacia lo hasta ahora inscrito es Benjamin. No es nuestra intención en este ensayo vincular el pensamiento de Benjamin con el de Loraux, por lo que sólo quisiera contrastar lo hasta aquí referido con el fragmento A de la tesis XVIII, así como con la tesis XVI de Sobre el concepto de historia:

El historicismo se contenta con establecer un nexo causal entre diversos momento históricos. Pero ningún hecho es ya histórico por el mero hecho de ser causa. Llega a serlo póstumamente gracias a circunstancias que pueden estar separadas del hecho por milenios. El historiador que parta de este supuesto dejará de desgranar la sucesión de circunstancias como un rosario entre los dedos. [Por otro lado, la tesis XVI expresa:] El historicismo postula una imagen "eterna" del pasado; el materialismo histórico, en cambio, una experiencia con ese pasado, que es única. Deja a otros malgastarse con la ramera "érase una vez" en el burdel del historicismo, mientras él se mantiene dueño de sus fuerzas: lo suficientemente hombre como para hacer saltar el continuum de la historia. ${ }^{5}$

Es de nuestro parecer que la apuesta por el anacronismo es la apuesta misma por dejar de ser un historiador que, con un rosario entre los dedos, o con la ramera del historicismo entre sus brazos (con quien por cierto no deja de saciar su carencia en un ciclo constante de gozo y desazón), afirme sin más el continuum de una historia del progreso constituida por la obligación del olvido. La afirmación de lo anacrónico es la escucha de la interpelación de lo negado. El anacronismo hace saltar el tiempo; desvela las discontinuidades repetitivas. De tal modo, sin ánimo de prolongar más esta mínima introducción, el "Elogio del anacronismo en la historia" de Loraux concluye con las siguientes palabras:

${ }^{4}$ Ibid., p. 215.

${ }^{5}$ Manuel Reyes Mate, Medianoche en la historia. Comentarios a las tesis de Walter Benjamin "Sobre el concepto de historia". 2a. ed. Madrid, Trotta, 2009, pp. 249 y 293. 
¿Por qué realizar el elogio del anacronismo cuando se es historiador? Quizá para invitar a los historiadores a que atiendan a nuestro tiempo de incertidumbres, centrándose en todo lo que desborda el tiempo de la narración ordenada: tanto en los desbocamientos como en los islotes de inmovilidad, que niegan el tiempo en la historia, pero que construyen el tiempo de la historia. ${ }^{6}$

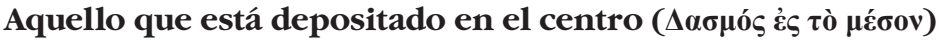

Una vez esbozada la idea desde la cual Loraux despliega su modo de trabajar y de experimentar la historia. Nos quisiéramos ocupar en este apartado de la manera en la que uno de los grandes helenistas franceses, Marcel Detienne, desarrolla uno de los tantos gérmenes que dio pauta a la expresión del régimen democrático en Atenas. Partimos de Detienne por la gran cercanía que tiene con Loraux, esto es, por la manera en que sus estudios influyeron a la helenista, quien de algún modo honra el trabajo realizado por Detienne, así como de toda la escuela de París, ${ }^{7}$ al lanzar tesis que difieren por su novedad. Pierre Vidal-Naquet, otro de los grandes nombres de la escuela de París, llega a afirmar sobre Loraux:

[Nicole] jugó un papel de suma importancia en el desarrollo del ámbito de los estudios griegos durante los años 1980-1995. Cuando la presenté en el EHESS, dije: "somos tres mosqueteros, dennos un d'Artagnan". Ella podía haber sido la nueva Jaqueline de Romilly, pero prefirió ser Nicole Loraux... y d'Artagnan. Era una mente extraordinaria. ${ }^{8}$

Loraux tenía en miras la búsqueda de una historia política renovada. La historia de lo político excluido. De lo político otro; mujer, esclavo y extranjero. Y dentro de esta historia de lo político excluido, la helenista se cuestionaba por la expresión del poder en sus temporalidades. Por la "presencia múltiple de tiempos y de ritmos heterogéneos en el corazón de las formas culturales y políticas". ${ }^{9}$ Cuestión que le exigía romper con toda posible aserción de lo

${ }^{6}$ N. Loraux, op. cit., p. 217.

${ }^{7}$ N. Loraux, "Back to the Greeks? Crónica de una lejana expedición a tierra conocida", en La guerra civil en Atenas. La política entre la sombra y la utopía. Trad. de Sara Vassallo. Madrid, Katz, 2008, pp. 29-49. Nos referimos a la escuela iniciada por el fundador de la antropología filosófica, Louis Gernet, y continuada por Jean-Pierre Vernant con la fundación en 1984 del Centre de recherches comparées sur les sociétés anciennes.

${ }^{8}$ Ibid., p. 15.

${ }^{9}$ Ibid., p. 215. 
Uno significante. De ese Uno que predetermina los acontecimientos y los interpreta a partir de un solo y mismo espacio-tiempo. Tal vez ahí resida la

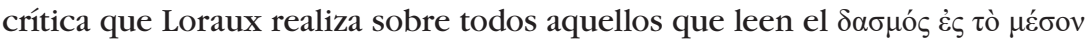
estudiado por Detienne como un modelo a partir del cual toda democracia debe reconocerse. Pero no vayamos tan rápido, refirámonos a la tesis de Detienne

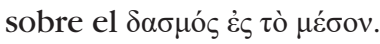

En Los maestros de verdad en la Grecia arcaica, Detienne se aboca a realizar una genealogía de la idea de verdad en la Grecia arcaica. Para ello estudia los contextos socio-históricos bajo los cuales portadores de verdad, en procesos aletúrgicos, disponen una zona de subjetivación que da cuenta de una forma de constitución del poder. Sobre ello Detienne afirma: "Nos ha parecido que el contexto socio-histórico podía contribuir a la genealogía de la idea de Verdad". ${ }^{10}$ Es interesante que en la Obertura de la obra, escrita posteriormente en 1994, Detienne señale que los estudios realizados por Foucault, en los cuales se hace manifiesta la "voluntad de verdad" diferencial dispuesta sobre las épocas, muy probablemente estén influidos por la investigación del helenista. ${ }^{11}$ Dejemos hasta aquí este planteamiento de Detienne, el cual nos conducirá a realizar otro análisis, y vislumbremos cómo se vincula el estudio

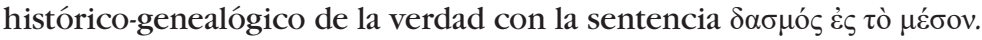

En su investigación, Detienne asevera: "Es posible, pues, preguntarse si la verdad, en tanto que categoría mental, no es solidaria de todo un sistema de pensamiento, si no es también solidaria de la vida material y de la vida social". ${ }^{12}$ Es de nuestro parecer que esta cita es clave para experimentar la investigación del helenista francés. Realizando estudios con aires etnográficos, Detienne vislumbra el vínculo entre la vida material y la vida social con la necesidad de verdad. Así, cursando discontinuidades históricas en la Grecia arcaica, destaca modos diferenciales de expresión de la verdad. No es la intención de este ensayo realizar un recuento de las épocas estudiadas por Detienne, por lo que, en lo que sigue, nos enfocaremos en ese periodo que el helenista dispone como la discontinuidad que le permitió a la ciudad, y al ágora específicamente, disponerse como el nuevo gozne de la verdad.

Así pues, Detienne nos habla de la lucha agonística entre dos espaciotiempos: el de la palabra mágico-religiosa y el de la palabra-diálogo. Lucha que

${ }^{10}$ Marcel Detienne, Los maestros de verdad en la Grecia arcaica. Trad. de Juan José Herrera. México, Sexto Piso, 2004, p. 11.

${ }^{11}$ Detienne afirma: "En 1970, en $E l$ orden del discurso, su 'lección inaugural en el Colegio de Francia', Michel Foucault descubrió en la Grecia arcaica el punto de partida que rige nuestra 'voluntad de saber' y, más exactamente, esta 'voluntad de verdad'. Muy probablemente, se refería al paisaje de lo verdadero que yo había dibujado en mi investigación" (ibid., p. 14).

${ }^{12}$ Ibid., p. 47. 
termina con el predominio de la palabra-diálogo. En el capítulo v, el helenista francés apunta:

Por absoluto que sea el imperio de la palabra mágico-religiosa, determinados medios sociales parecen haber escapado a él. Desde la época más remota están en posesión de otro tipo de palabra: la palabra-diálogo. Estos dos tiempos de palabra se oponen en toda una serie de puntos: la primera es eficaz, intemporal; inseparable de conductas y de valores simbólicos; privilegio de un tipo de hombre excepcional. Por el contrario, la palabra-diálogo está secularizada, complementaria de la acción, inscrita en el tiempo, provista de una autonomía propia y ampliada a las dimensiones de un grupo social. Este grupo social está constituido por los hombres especializados en la función guerrera, cuyo estatuto particular parece prolongarse desde la época miscénica hasta la reforma hoplita que señala el fin del guerrero como individuo particular y la extensión de sus privilegios al ciudadano de la Ciudad. ${ }^{13}$

La palabra mágico-religiosa, propia de los individuos excepcionales, y por ende de una verdad eterna e intemporal, estalla ante una acción inscrita en el tiempo. Un modo diferencial de la verdad aparece en el horizonte, y con éste, otro modo de subjetivación crea un nuevo espacio de expresión del poder. Los guerreros, cuyo estatuto va cambiando hasta la reforma hoplita, con sus prácticas (como los juegos funerarios, los repartos de botín y las asambleas deliberativas) rompen con privilegios aristocráticos y constituyen una nueva forma de politicidad donde un nuevo lugar se constituye como el territorio legítimo de decisión, soberanía y verdad. ${ }^{14}$ Detienne afirma: "el espacio dibujado por la asamblea no es un espacio informe, sino un espacio centrado: cuando Aquiles trae los premios que, por generosidad de príncipe, pone en

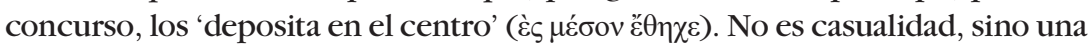
costumbre muy atestiguada". ${ }^{15} \mathrm{El} \mu \varepsilon \dot{\sigma o v}$ aparece en esta discontinuidad epocal como el origen y fundamento de la verdad y, por ende, como el núcleo de la

${ }^{13}$ Ibid., p. 137.

${ }^{14}$ Detienne detalla: "Es la falange, la formación hoplita en la que cada combatiente ocupa un lugar en la fila, en la que cada ciudadano-soldado es concebido como unidad intercambiable, lo que permite la democratización de la función guerrera y solidariamente, la adquisición, por parte de un grupo de 'escogidos', de un mayor número de privilegios políticos hasta entonces reservados a la aristocracia. Fundándose en progresos tecnológicos, la reforma hoplita no se lleva a cabo solamente en el orden técnico, es también, a la vez, producto y agente de nuevas estructuras mentales, las mismas que dibujan el modelo de la ciudad griega" (ibid., p. 158).

${ }^{15}$ Ibid., p. 139. 
comunidad. Se trata de un reparto legítimo. "El reparto del botín es $\delta \alpha \sigma \mu o ́ \varsigma$ $\dot{\varepsilon} \varsigma$ $\tau$ el centro"”. ${ }^{16}$ Dicho reparto no es exclusivo de riqueza material. Se trata de un reparto de soberanía. Un reparto de lo político, de lo común. Sobre dicha representación del espacio Detienne formula:

Desde la Epopeya, esta representación del espacio es solidaria de dos nociones complementarias: la noción de publicidad y la de comunidad. El meson es el punto común a todos los hombres colocados en círculo. Todos los bienes colocados en este punto central son cosas comunes [...]; las palabras que se pronuncian allí son del mismo tipo: conciernen a los intereses comunes. Punto común, el meson es por eso mismo el lugar público por excelencia: por su situación geográfica, es sinónimo

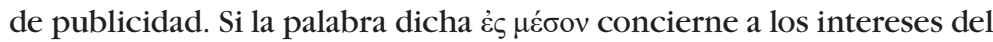
grupo, se dirige necesariamente a todos los miembros de la asamblea. También el reparto del botín exige publicidad: cada uno va a tomar su parte bajo la mirada de todos. ${ }^{17}$

Publicidad y comunidad. Voluntad de expresar la verdadera y soberana fundamentación de lo común. Tal es la expresión del $\mu$ ćбov durante la constitución de subjetivación del guerrero. Para apropiarse del botín hay que hablar justamente. Hay que expresar la verdad ante la comunidad. Detienne señala:

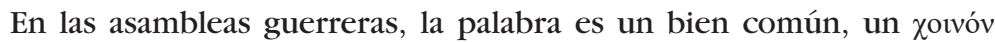
depositado "en el centro". Cada uno se apodera de ella por turnos con el acuerdo de sus iguales: de pie, en el centro de la asamblea, el orador se halla a igual distancia de aquellos que le escuchan, y cada uno se encuentra mediante su relación con él, al menos idealmente, en una situación de igualdad y reciprocidad. ${ }^{18}$

La palabra como bien común depositada en el centro produce isonomía. Turnos entre iguales. Desaparición de jerarquías. Disposición agónica de la palabra. Tales son las prácticas que reconfiguran la voluntad de verdad durante un determinado periodo en los territorios hoplitas. No más rango escalonado para la palabra mágico-religiosa. ${ }^{19}$ Para Detienne estamos en la génesis de lo

${ }^{16}$ Ibid., p. 141.

${ }^{17}$ Ibid., p. 148.

${ }^{18}$ Ibid., p. 151.

${ }^{19} C f$. Detienne escribe: "Instrumento de diálogo, este tipo de palabra no obtiene ya su eficacia de la puesta en juego de fuerzas religiosas que trascienden a los hombres. Se funda esencialmente en el acuerdo del grupo social que se manifiesta mediante la 
que posteriormente se constituirá como el ágora, y con ésta, la institucionalización de la ciudad democrática. ${ }^{20}$ El helenista asevera:

La clase guerrera, grupo social cerrado en sí mismo, desemboca, en el devenir de la sociedad griega, en la institución más nueva, más decisiva: la ciudad, como sistema de instituciones y como arquitectura espiritual. En el medio de los guerreros profesionales se esbozan determinadas concepciones esenciales del primer pensamiento político de los griegos: el ideal de isonomía, representación de un espacio centrado y simétrico, distinción entre intereses personales e intereses colectivos. ${ }^{21}$

El ágora, como ese espacio centrado y simétrico, expresa lo común determinado geométricamente, y con ello, la conformación estratégica de un nuevo modo del poder. Detienne acentúa:

Es, en definitiva, en las deliberaciones de la clase guerrera donde se forja la oposición, capital en el vocabulario de las asambleas políticas, entre los intereses colectivos y los intereses personales. Poner a discusión la conducta a seguir se dice en griego mediante la expresión

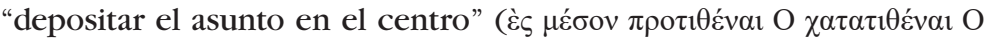

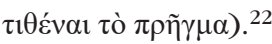

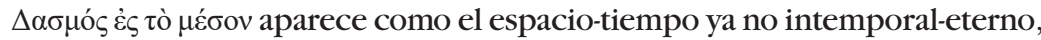

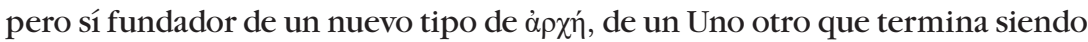
en su diferencia lo Mismo. Un nuevo gozne para la expresión de la voluntad de verdad. El gozne de la ciudad democrática.

Frente a esta formación de la ciudad democrática que encuentra al ágora como gozne soberano, Loraux se dispondrá a hacer una distinción en cuanto a la manera de realizar estudios se refiere, y en su artículo: "Back to the Greeks? Crónica de una lejana expedición a tierra conocida”, apoyará la interpretación de los antropólogos frente a la de los historiadores:

aprobación y la desaprobación. Será en las asambleas militares donde, por primera vez, la participación del grupo militar funde el valor de una palabra. Será allí donde se prepare el futuro estatuto de la palabra jurídica o de la palabra filosófica, de la palabra que se somete a la 'publicidad' y que obtiene su fuerza del asentimiento de un grupo social" (ibid., p. 152).

${ }^{20}$ Detienne apunta: "Juegos funerarios, reparto de botín, asambleas deliberativas, en tanto que instituciones que forman un plano de pensamiento prepolítico. El espacio circular y simétrico que transmiten estas instituciones encuentra su expresión puramente política en el espacio social de la ciudad, centrado en el Ágora" (ibid., p. 155).

${ }^{21}$ Ibid., p. 153.

22 Ibid., p. 156. 
Los antropólogos de Grecia, [...] han hecho su elección. Contra la Grecia de los ideales humanistas, que su historia asocia con la ciudad de los historiadores, contra el prestigio de la identidad de lo mismo, que tiene mucho que ver con la política y la razón griegas, quisieron descentrar el objeto "ciudad" y se pusieron a buscar eso que ocupa el lugar del otro en las ciudades de la Grecia arcaica y clásica, a saber: el tiempo suspendido del rito, ese tiempo otro respecto del político, pero sobre todo esas alteridades respecto del ciudadano que son los jóvenes, las mujeres, los esclavos e incluso los artesanos, a la espera de que arqueros y soldados armados de escudos, los otros de los hoplitas, vengan a sumarse al batallón de la alteridad. ${ }^{23}$

Ir a la búsqueda de lo otro de los hoplitas será ir más allá de la censura de lo político. Más allá de la interpretación de una ciudad esbozada a modo.

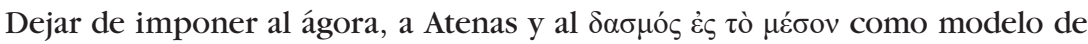
reconocimiento. Y es que la pregunta que se hace la helenista es: "¿lo político equivalente a la ciudad en paz?”. ${ }^{24}$ En otras palabras: ¿la democracia implica consenso entre iguales a partir de un gozne soberano que determina un solo y mismo espacio-tiempo? Junto a Loraux podemos afirmar que hay un eslabón ausente. Y es que el $\mu \varepsilon ́ \sigma o v$ y la iconografía referente a éste "parece postular la

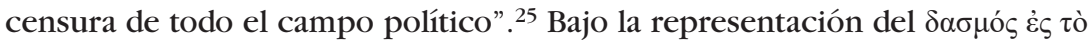

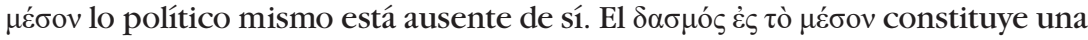

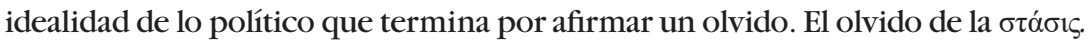
En palabras de Loraux: "Enraizado en el meson, lo político se concibe como si hubiera superado los conflictos por así decir de una vez por todas partes". ${ }^{26}$

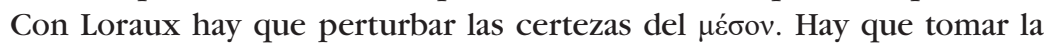
decisión "de romper el encanto de este modelo. [...Renunciar], por ejemplo, a la idea de que es preciso atenerse a las palabras de los griegos; sometamos sus enunciados a preguntas que sus discursos callaron". ${ }^{27}$ Hay que buscar lo no-dicho en lo dicho; lo oculto en lo des-oculto. Loraux incita a hacer estallar la soberanía del $\mu \varepsilon ́ \sigma o v$ como figura de lo mismo. Y es que el $\mu \varepsilon ́ \sigma o v$ aparece como el:

[...] lugar geométrico de una vida política sin choques [...] consiste en reunir a ciudadanos intercambiables en la medida en que todos, en principio, son semejantes unos a otros. Nunca se elogiará lo bastante

${ }^{23}$ Nicole Loraux, La ciudad dividida. El olvido en la memoria de Atenas. Trad. de Sara Vassallo. Madrid, Katz, 2008, p. 44.

${ }^{24}$ Ibid., p. 51.

${ }^{25}$ Ibid., p. 50.

${ }^{26}$ Idem.

${ }^{27}$ Ibid., p. 53. 
la potente atracción de ese meson isomorfo [...]. Esa atracción, a la vez conceptual y política, se ejerció de entrada sobre todos aquellos que no estaban satisfechos con la institución oficial de la historia griega, con su concepción empírica e incluso anecdótica de la ciudad. Pero en su ejemplar estabilidad, ese modelo ha obstaculizado el estudio de los disfuncionamientos que hacen la historia: así, por ejemplo, nunca repetiremos lo suficiente que como lugar vacío que exige un poder puramente simbólico (como el de la rotación de las funciones y los cargos públicos), el meson se convierte fácilmente, a poco que se debilite lo simbólico, en un lugar que es necesario ocupar realmente, es decir, un lugar que debe ser conquistado por un grupo $[\ldots]^{28}$

Mćбov isomorfo que vuelve a todos intercambiables. Que vuelve a todos semejantes; dispuestos sobre un modelo de analogía simple en donde la oposición sólo se atenúa y declara con los que se encuentran afuera. Por esto que

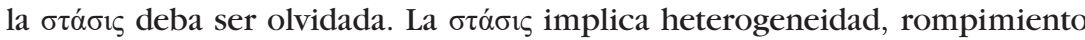

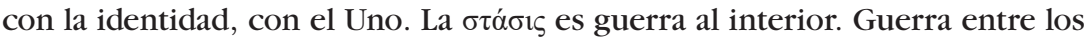
autóctonos. Guerra en el $\mu \varepsilon ́ \sigma o v$. La gran atracción conceptual y política que ejerce el $\mu \varepsilon ́ \sigma o v$ impone un solo ritmo; una sola cadencia de la palabra. ${ }^{29} \mathrm{Con}$

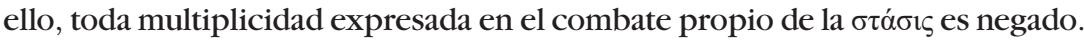

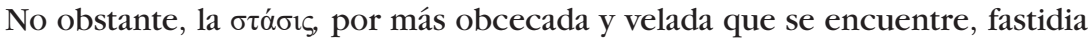
e incomoda a ese lugar vacío. Como el no-ser en el pensamiento platónico, la $\sigma \tau \alpha ́ \sigma ı \varsigma$ vuelve. Se repite en su diferencia para expresar las heridas del $\mu \varepsilon ́ \sigma o v$.

\section{A modo de conclusión. Amnesia y amnistía al servicio de la democracia: las Erinias al pie del Areópago}

El $\mu \varepsilon ́ \sigma o v$ sirve como fundamento de la polis del consenso cuando es interpretado de manera simple. Bajo el $\mu \varepsilon ́ \sigma o v$ la comunidad es apaciguada por un cimiento. El $\mu \varepsilon ́ \sigma o v$ ofrece seguridad. Tal es su peligro. Loraux llega a apuntar que la "polis del consenso sirve de ideología a la ciudad dividida ya que su figura tranquilizadora niega hasta la posibilidad de pensar las divisiones reales" ${ }^{30} \mathrm{y}$,

${ }^{28}$ Ibid., p. 52.

${ }^{29}$ Loraux señala: "el reparto isonómico se transformará entonces en una figura, una figura que la colectividad de ciudadanos desea darse a sí misma bajo el signo tranquilizador de lo intercambiable. Algo así como una utopía para recubrir lo que la ciudad no quiere ver y ni siquiera pensar, es decir, que en el núcleo de lo político, el conflicto existe en forma virtual (y a veces real), y que la división en dos, esa calamidad, es la otra cara de la bella Ciudad-una" (ibid., p. 53).

${ }^{30}$ Ibid., p. 29. 
más aún, lo político afianzado en el reparto igualitario neutraliza lo político mismo, volviéndolo inmóvil. La ciudad misma se estratifica. Está en reposo. El ámbito consensual recubre el conflicto, la vehemencia misma de lo común. En el $\mu \varepsilon ́ \sigma o v$, el político es quien consensualmente asiente el olvido. Bajo

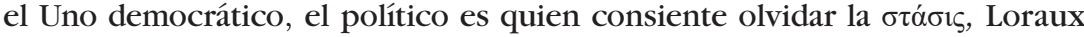
afirma: "la democracia deniega su historicidad pero logra con ello echar raíces en un origen inmemorial tan noble como natural". ${ }^{31}$ La democracia entonces dispone en el $\mu \varepsilon \dot{\sigma o v}$ una fundación inmemorial.

Como se entrevé, se trata de un juego entre la amnesia y la amnistía. La memoria se vuelve peligrosa para la identidad de la ciudad, para su sobriedad y detención. La memoria identitaria de la polis está al servicio del olvido de la

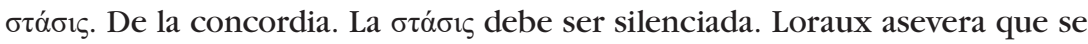
trata de una "memoria negada, pero memoria al fin". ${ }^{32}$ Bajo la acepción simple del $\mu \varepsilon ́ \sigma o v$ hay que jurar que no se recordará. Se trata de un juramento por la identidad, la semejanza y la analogía. Jurar por lo Mismo. Jurar por quien se es. La paradoja entonces reside en que no se puede olvidar no olvidar.

Pero detengámonos un momento en esta ilación y, junto a Loraux, veamos

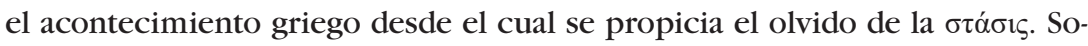
bre ello la helenista nos refiere:

En su comienzo, nuestro proyecto era comprender un hecho político, es decir, qué es lo que llevaba a los atenienses en el año 403 a. C. a prestar juramento de "no recordar los males del pasado" [...]. En el comienzo, pues, el proyecto era comprender un momento clave de la historia política de Atenas: después de la derrota final en la guerra del Peloponeso, después del golpe de Estado oligárquico de los Treinta "tiranos" y sus exacciones, se produce el retorno triunfante de los resistentes demócratas, que se vuelven a encontrar con sus conciudadanos, adversarios de ayer, para jurar con ellos olvidar el pasado de común acuerdo. ${ }^{33}$

Nos colocamos entonces en el 403 a. C., tras la tiranía de los Treinta, los demócratas ganadores prestan el juramento de no recordar los males del pasado. Aristóteles en el apartado titulado: "Pacto entre los ciudadanos de Atenas y las gentes del Pireo" de su Constitución de Atenas, afirma que los demócratas aceptan pagar la deuda de guerra solicitada por los Treinta a Esparta para

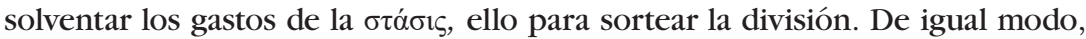
Aristóteles asevera que, a partir de la victoria demócrata: "Nadie podrá exigir

\footnotetext{
${ }^{31}$ Ibid., p. 61.

${ }^{32}$ Ibid., p. 146.

${ }^{33}$ Ibid., p. 15.
} 
represalias contra nadie por las actuaciones que haya tenido en el pasado", ${ }^{34}$ y cuando en una ocasión un individuo se puso a proclamar represarías contra los Treinta, Trasíbulo consiguió que "a ese tal lo condenaran a muerte sin juicio, argumentando ante el Consejo que había llegado al momento de demostrar si querían conservar la democracia y ser fieles a los juramentos que habían presentado". 35

El 403 a. C. se revela como una manifestación, entre otras muchas, del

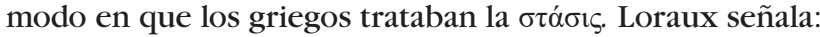

La guerra civil es, para un griego, la abominación de la desolación [...] stásis [...] el término no designa, etimológicamente, otra cosa que una posición, el hecho de que la posición se convierte en partido, que el partido se constituye necesariamente con fines de insurrección, que una facción exige indefinidamente la existencia de otra facción y que, por consiguiente, la guerra civil se enardece. ${ }^{36}$

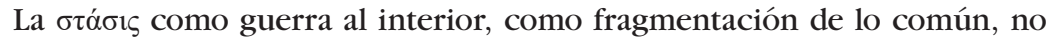
es intuida como lo político en devenir, sino como una enfermedad; como un castigo. ${ }^{37}$ En La ciudad dividida leemos:

[...] conviene observar, aunque se lo olvide en general, que cuando condena la stásis (como suele hacerlo regularmente), el pensamiento griego de la ciudad debe borrar a toda costa su origen político -por ejemplo cuando asimila a una enfermedad, nósos, caída funestamente del cielo- para preservar esa instancia política consensual que sería lo político propiamente dicho. ${ }^{38}$

La ciudad griega democrática deniega el conflicto. Huye a pensar que el conflicto es connatural a lo político, pues, de algún modo, abre la posibilidad a que una identidad fija, fundadora, se desfragmente.

${ }^{34}$ Aristóteles, "Constitución de Atenas", en Constituciones políticas griegas. Trad. de Antonio Guzmán. Madrid, Alianza, 2007, p. 93-[39-6].

${ }^{35}$ Ibid., p. 95-[40-2].

${ }^{36}$ N. Loraux, La ciudad dividida. El olvido en la memoria de Atenas, p. 23.

${ }^{37}$ La helenista apunta: "la stásis es parte integrante de lo político griego -y me atrevo a decir: su parte más importante-, incluso si los propios griegos intentan regularmente negar la dimensión política de la guerra civil, tratándola como una calamidad meteorológica o epidémica, pero siempre caída del cielo, o sea, extraña al funcionamiento normal de la ciudad, el cual sólo podría ser pacífico desde esta perspectiva" (N. Loraux, La guerra civil en Atenas, p. 87).

${ }^{38}$ N. Loraux, La ciudad dividida. El olvido en la memoria de Atenas, p. 25. 
Para ir cerrando estás líneas, traigamos a colación de nueva cuenta la noción de anacronismo. Recordemos: ¿por qué realizar el elogio del anacronismo cuando se es historiador? Para atender las incertidumbres de nuestro tiempo. Y es que hoy se renueva diferencialmente ese movimiento democrático instaurado en el $\mu$ Éøov que obliga a repetir el olvido. A exigir "un esfuerzo colectivo para ir hacia delante y superar los momentos de dolor". Amnistía amnésica. La ciudad como sujeto sólo puede existir si se le atribuye una sola y misma identidad. Loraux apunta: "Que la reconciliación existe en la Atenas de los últimos años del siglo v a. C. lo muestra con suficiente claridad. Pero eso no quiere decir que se pueda olvidar impunemente el conflicto. Quisiera mostrar ahora, justamente, cuál fue el precio que la democracia restaurada tuvo que pagar por ese olvido” ${ }^{39}$ ¿Cuál es el precio que pagamos por el olvido? ¿A qué se debe esta necesidad por un mito fundacional? ¿Qué condiciona la identidad de la ciudad? ¿Por qué repetimos constantemente esta amnistía cívica? ${ }^{40} ¿$ ¿ué intensidades y espacio-tiempos nos conllevan a hacerlo? ¿Por qué recubrimos constantemente las desgracias por ficciones dispuestas como verdades históricas? ${ }^{41}$

Para finalizar, dejando abierta esta indagación, traigamos de la mano de Loraux el final de las Euménides de Esquilo, poeta trágico que nos da cuenta de cómo es que las Erinias se transforman en Euménides, es decir, de cómo

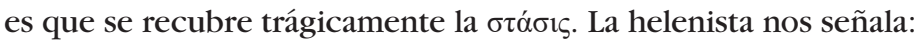

Leamos una vez más a Esquilo. Lo que él relata ocurre, o se supone que ocurre, al comienzo de la ciudad. Las Erinias siguen amenazando aún a Orestes con su cólera y con "ese vínculo para el pensamiento" [...] en el que encierran a sus víctimas. Pero ya se prepara el momento en que, vencidas y convencidas por Atenea, se instalarán al pie del Areópago, para que la ciudad ateniense se compenetre con ellas y olvide luego lo que son. De ahora en más el espíritu de stásis vigila y se controla. Desde ahora llamamos Euménides ("benevolentes") a las Erinias. ${ }^{42}$

Así pues, la "instalación de las Erinias al pie del Areópago simboliza [...] la presencia del terror y de la cólera en una ciudad domesticada pero siempre

${ }^{39}$ Ibid., p. 193.

${ }^{40}$ La helenista nos señala: "Mi hipótesis es que, más allá de todas las denegaciones $\mathrm{y}$ todos los olvidos, lo que es preciso olvidar o denegar es el hecho de que la stásis sea connatural a lo político griego. Olvidar el pasado sería entonces, en el contexto de cada amnistía cívica, repetir un olvido muy antiguo" (ibid., p. 64).

${ }^{41}$ Loraux apunta: "la ficción diría: en el principio era el conflicto, después vino la polis, que instituyó la paz para los ciudadanos... Y sin fin, la amnistía restablecería, dicen, la ciudad protegiéndola de las desgracias recientes" (ibid., p. 155).

${ }^{42}$ Ibid., p. 119. 
amenazada". 43 El olvido de lo político, por parte de la democracia, domestica a la ciudad a través de lo Uno ficcional. Y cuando el relato de lo Uno se deshilacha, se solicita de la manera más atenta, que se vuelva a afirmar el olvido. Esa amnistía amnésica que se repite. Ante tal problemática Loraux señala:

A la inversa de la construcción clásica de un paradigma de ciudad que toma al Uno como modelo, el relato insistirá cada vez en sacar a la luz, por debajo de la belleza de la construcción, las líneas de un pensamiento que el discurso oficial sobre la comunidad recubre y quizá reprime. Por debajo de la expulsión de la stásis, se comprueba con temor que la guerra civil es connatural a la ciudad y hasta fundadora de lo político en la medida en que es, precisamente, común. ${ }^{44}$

El anacronismo histórico se presenta entonces como una manera de hacer saltar el continuum ficcional de lo Uno. Lo que se recuerda es el temor connatural de pertenecer a lo común. Tal vez sea afrontándolo, afirmándolo, que se llegue a constituir otra perspectiva de la política. Una política de lo múltiple. De la diferencia. Que ya no predetermine su devenir. Una política fuera de toda lógica identitaria. Política sin $\mu$ ćoov.

${ }^{43}$ Ibid., p. 39.

${ }^{44}$ Ibid., p. 96. 